stage of our knowledge to say what factors actually are involved in the decrease of swelling and the retardation of diffusion. It may not be superfluous to point out here that the similarity between the equation developed on page igi I to express the relationship between relative retardation and sugar concentration, and the adsorption equation, is purely formal, since the concentration involved in the latter is the concentration of the adsorbed substance after equilibrium has been reached.

\title{
Summary.
}

I. The diffusion of hydrogen ion from various organic and inorgan... acids into gelatin containing sugar (glucose, saccharose or lactose) has been studied and found to be markedly retarded by the presence of the sugar.

2. In agreement with the diffusion law, the ratio of the distance of diffusion to the square root of the time has been found in general to be a constant in gelatin with, as well as without, sugar.

3. The decrease in this ratio with increasing sugar concentration has been found to be not proportional to the concentration of the sugar, but relatively greater for the smaller concentrations. The experimental relation may be approximately expressed by the equation

$$
\left(\Delta / K_{0}\right)^{n}=a c
$$

where $\Delta / K_{0}$ represents the relative retardation, $a$ and $n$ are constants, and $c$ is the concentration of the sugar.

4. Sodium chloride added to the gelatin also retards the diffusion of acids, but the retardation is less than that caused by sugar in equal concentration. This is the reverse of their effect in reducing the acid swelling of gelatin, in which sodium chloride is more effective than sugar.

5. The mechanism of the retardation is briefly discussed.

Chicago, Itr.l.

[CONTRIBUTION FROM THE LABORATORY OF THE DODGE AND OLCOTT Co.]

\section{THE ISOMERIC LACTONES, CARYOPHYLLIN AND URSON.}

By Francrs D. Dodge.

Received August 3, 1918.

Caryophyllin, a crystalline compound occurring in clove buds, was first isolated by Baget and Lodibert, in $1825 .{ }^{1}$ The empirical formula was found to be $\mathrm{C}_{10} \mathrm{H}_{16} \mathrm{O}$, and the substance was regarded as an isomeride of camphor. It was subsequently studied by Dumas, ${ }^{2}$ Bonastre, ${ }^{3}$ and Mylius, ${ }^{4}$ the latter of whom suggested the formula $\mathrm{C}_{20} \mathrm{H}_{32} \mathrm{O}_{2}$ as agreeing

$1 \mathrm{~J}$. physik. Chem., II, IOI (1825).

2 Ann. chim. phys., [3] 53, 166 (1858).

3 J. Phys. Chem., 20, 565 (1834).

4 Ber., 6, 1053 (1873). 
better with the high melting point. Muspratt ${ }^{1}$ and Martius ${ }^{2}$ have also given some details as to the preparation and purification.

The first clue to the structure of caryophyllin was obtained by Hjelt, ${ }^{3}$ who prepared a crystalline acetyl derivative, melting at $184^{\circ}(?)$. From the study of the chlorination products, resulting from the action of phosphorus pentachloride, he deduced, as most probable, the formula $\left(\mathrm{C}_{10} \mathrm{H}_{16} \mathrm{O}\right)_{4}$.

Meyer and Honigschmid ${ }^{4}$ found that caryophyllin melted at $295^{\circ}$ in a closed capillary, and sublimed without decomposition in vacuo. Analysis of the compound, dried at $110^{\circ}$, indicated the formula $\left(\mathrm{C}_{10} \mathrm{H}_{16} \mathrm{O}\right)_{n}$, and from molecular-weight determinations by the boiling-point method it seemed probable that $n=4$. The acetate, after recrystallization from dilute methyl alcohol, melted at $268-271^{\circ}$, in closed tube (softening at $245^{\circ}$ ). From the saponification value of the acetate, he concluded that caryophyllin must be considered a tetratomic alcohol, and that the hydroxyl groups are probably primary and secondary. Oxidation with permanganate, chromic acid, or persulfate, led to no definite results.

Herzog ${ }^{5}$ prepared from caryophyllin and diphenyl urea chloride in pyridine solution, a carbaminic ester, melting at $137^{-1} 3^{\circ}$. This compound yielded caryophyllin and diphenylamine on hydrolysis, and the analysis appeared to indicate the composition $\mathrm{C}_{40} \mathrm{H}_{63} \mathrm{O}_{4} \cdot \mathrm{CO} \cdot \mathrm{N}\left(\mathrm{C}_{6} \mathrm{H}_{5}\right)_{2}$, thus confirming Meyer's formula. An acetyl derivative was also obtained, which darkened at $210^{\circ}$, and melted at $225^{\circ}$. The elementary analysis of this compound, however, agreed better with the assumption of a diacetate, $\mathrm{C}_{40} \mathrm{H}_{62} \mathrm{O}_{4}\left(\mathrm{C}_{2} \mathrm{H}_{3} \mathrm{O}\right)_{2}$, rather than a tetra-acetate, as found by Meyer. A benzoate was also prepared by the action of benzoic anhydride at $200^{\circ}$, which, after crystallization from dilute alcohol, showed a melting point of $185^{\circ}$ (softening at $173^{\circ}$ ).

Herzog appears to have been the first to note that caryophyllin is capable of forming crystalline combinations with the alkaline hydroxides. He obtained the potassium salt by adding strong potassium hydroxide to an ethereal solution of caryophyllin, and prepared a barium salt in an analogous manner, but apparently made no analyses of either. By oxidation of caryophyllin with chromic acid, in acetic acid solution, a product was obtained which was insoluble in alkalies, and yielded apparently a crystalline oxime and a semicarbazone.

The results obtained by Herzog seemed to the writer to be incompatible with the tetratomic alcohol formula proposed by Meyer, and some preliminary experiments having indicated a rather different molecular struc-

I Jahresb., 1850, p. 510 .

${ }^{2}$ Am. J. Chem., 32, p. 65.

${ }^{3}$ Ber., I3, 800 (1880).

4 Monatsh., 26, 379 (1905).

5 Ber. pharm. Ges., 15, I21 (1905). 
ture, the compound was examined more thoroughly; and, as will appear, the data collected apparently call for a revision of the conclusions of previous investigators.

\section{Preparation of Caryophyllin.}

The older published methods for the isolation of caryophyllin do not readily yield a pure product. Herzog had already roted this fact, and, in confirmation, the writer found it practically impossible to obtain caryophyllin in satisfactory purity by simple recrystallization from alcohol or ether. It is always contaminated with amorphous matter, which becomes evident when it is dissolved in alcoholic potassium hydroxide. The alkaline salts, however, are easily purified, and from these a pure caryophyllin can be prepared without difficulty.

The potassium salt exhibits rather unusual properties, as regards solubility. It is practically insoluble in water, but is gradually decomposed by boiling water, with liberation of alkali. It is difficultly soluble in cold ethyl alcohol, but is very soluble in methyl alcohol, and from the latter solution, if not too dilute, it is precipitated in crystals by the addition of water. The sodium salt crystallizes from methyl alcohol in fine, large, efflorescent prisms.

Utilizing the properties of the salts, the purification of caryophyllin may be effected in various ways: For example, if 10 grams of the crude substance be heated with Ioo cc. of $0.5 \mathrm{~N}$ alcoholic potassium hydroxide and $50 \mathrm{cc}$. of water for an hour or so, the solution filtered while hot, and then allowed to cool slowly, large crystals of the potassium salt separate. These generally contain still some amorphous impurity, which is removed by dissolving in three parts of cold methyl alcohol, filtering, and precipitating again by the gradual addition of water. The salt thus obtained is snow-white, and completely soluble in methyl alcohol. From the salt, caryophyllin is obtained by dissolving in ten parts methyl alcohol, adding a slight excess of strong hydrochloric acid, heating to boiling, and then allowing to crystallize slowly. The resulting magma is filtered by suction, washed with methyl alcohol, and finally recrystallized from thirtyfive parts of boiling ethyl alcohol.

Or, the crude caryophyllin may be dissolved in twenty parts of methyl alcohol, with sufficient alcoholic potassium hydroxide to make the solutions slightly alkaline, and the solution decolorized by the gradual addition of strong aqueous permanganate. Not more than about one part of the latter should be used; if the solution is further diluted, the caryophyllin salt is liable to separate. From the filtrate, caryophyllin is obtained by acidifying, as above.

\section{Properties of Caryophyllin.}

Caryophyllin crystallizes from boiling ethyl alcohol in white needles, very resinous to the touch. From dilute solutions, characteristic rosets 
are slowly deposited. The crystals appear to contain two molecules of water.

1. 4.9 I 1 g. air-dry, lost at $110^{\circ}, 0.3715$ g. or $7.56 \%$

2. $4.0155 \mathrm{~g}$. air-dry, lost at $110^{\circ}, 0.3114 \mathrm{~g}$. or $7.76 \%$ Averaged $7.40 \%$.

3. 5.465 g. air-dry, lost at $110^{\circ}, 0.375$ g. or $6.94 \%$

(Calc. for $2 \mathrm{H}_{2} \mathrm{O}, 7.31 \%$.)

The anhydrous compound melted at about $3 \mathrm{IO}^{\circ}$ (corr.) to a dark liquid, without other evidence of decomposition. In a vacuum tube at $280-$ $300^{\circ}$, it sublimes in characteristic rosets. It also sublimes with partial decomposition, when heated in open tube at above $310^{\circ}$.

Caryophyllin is practically insoluble in water. It is soluble in about 35 parts boiling $95 \%$ alcohol, and, at $20^{\circ}$, is soluble in 106 parts $95 \%$ alcohol, in 65 parts ether, in I 8 parts chloroform, in 180 parts acetone, and 235 parts methyl alcohol. The alcoholic solutions are neutral to litmus.

It is insoluble in aqueous alkalies, but on standing or digesting with alkaline hydroxide solution, is partly converted into the corresponding salt. It is readily soluble in 4 parts of $0.5 \mathrm{~N}$ methyl alcoholic potassium hydroxide.

Composition.- In view of the fairly general concordance of the analyses as described in the introduction, the writer considered it hardly necessary to repeat this work.

Rotation.-Caryophyllin is optically active. An alcoholic solution, containing $0.077 \mathrm{~g}$. in $10 \mathrm{cc}$., showed a rotation in a $100 \mathrm{~mm}$. tube, of $0.42^{\circ}$, from which $[\alpha]_{D}=+54.5^{\circ}$. Owing to the dilution this result cannot be regarded as exact.

In solution as potassium salt, the following rotations were noted:

$0.224 \mathrm{~g}$. dry $\mathrm{K}$ salt in ro cc. $95 \%$ ethyl alcohol $+\mathrm{r.42} 2^{\circ}$ at $20^{\circ}[\alpha]_{\mathrm{D}}=+63.40^{\circ}$

$0.9519 \mathrm{~g}$. dry $\mathrm{K}$ salt in 1o cc. methyl alcohol $+6.45^{\circ}$ at $24.5^{\circ}[\alpha]_{\mathrm{D}}=+67.70^{\circ}$

That caryophyllin behaves like a weak acid, appears to have escaped the observation of the earlier investigators. As already noted, Meyer believed it to be a tetratomic alcohol. Herzog, indeed, reported the formation of crystalline potassium and barium salts, but, rather strangely, appeared to agree with Meyer as to the alcohol formula.

In alcoholic solution, however, caryophyllin may be titrated, with phenolphthalein as indicator. Neutralization is immediate, but the end reaction is not as sharp as one ordinarily finds with organic acids, due, undoubtedly to the fact that the compound is not a true acid, but a lactone. To secure accuracy in the titration, it is well to chill the solution, toward the end, until the greater part of the potassium salt has crystallized out, when the titration may be finished. An alcoholic solution of the salt, exactly neutral when cold, becomes alkaline when heated; a reaction frequently observed with lactones.

Numerous titrations of caryophyllin of varying purity gave acid values 
from II 8 to I22. The specially purified and thoroughly dried preparation gave the following results:
r. 2.310 g. required I0.3 cc. $0.5 N \mathrm{KOH}$. Acid value, 124.8
2. 2.223 g. required $9.77 \mathrm{cc} .0 .5 \mathrm{~N} \mathrm{KOH}$. Acid value, 123.0
3. $2.0085 \mathrm{~g}$. required $8.93 \mathrm{cc} .0 .5 \mathrm{~N} \mathrm{KOH}$. Acid value, 124.4

We have here data by which to determine the molecular weight. Assuming the formula $\left(\mathrm{C}_{10} \mathrm{H}_{16} \mathrm{O}\right)_{x}$, and the presence of one carboxyl group, $x$ is evidently 3 , and the formula becomes $\mathrm{C}_{30} \mathrm{H}_{48} \mathrm{O}_{i}$, with acid value, I 22.9 .

For comparison, assuming one $\mathrm{COOH}$ :

$$
\begin{aligned}
& \text { Acid value of }\left(\mathrm{C}_{10} \mathrm{H}_{16} \mathrm{O}\right)_{2}, 184.4 \\
& \text { Acid value of }\left(\mathrm{C}_{10} \mathrm{H}_{16} \mathrm{O}\right)_{3}, \mathrm{I} 22.9 \\
& \text { Acid value of }\left(\mathrm{C}_{10} \mathrm{H}_{16} \mathrm{O}\right)_{4}, \quad 92.2
\end{aligned}
$$

There can be little doubt, therefore, that the formula $\mathrm{C}_{30} \mathrm{H}_{48} \mathrm{O}_{3}$, with one carboxyl, or lactone group, represents the molecule of caryophyllin. The third oxygen atom is evidently present as hydroxyl, and two possibilities are to be considered:

$$
\text { I. } \mathrm{C}_{29} \mathrm{H}_{48}\left\{\begin{array}{l}
\mathrm{OH} \\
\mathrm{COOH}
\end{array}\right.
$$

The first represents a mono-oxy-acid; the second, a lactone of a dioxy-acid. The properties of the alkaline salts, to be described, decidedly indicated the lactone structure, and it appeared probable that an examination of the acetylation product might throw further light on this point. The first formula should give a mono-acetyl derivative, the second, possibly two, depending on the stability of the lactone ring. In fact, as will be shown, two well characterized acetyl compounds were obtained, thus confirming the second, or lactone formula.

\section{Potassium Salt.}

This characteristic compound may be readily prepared by slow concentration of the alcoholic solution, or by dissolving caryophyllin in a hot mixture of to parts $0.5 \mathrm{~N}$ alcoholic potassium hydroxide and 5 parts water, from which solution, on cooling, well-defined prisms of the salt are obtained.

The crystals appear to contain I. $5 \mathrm{H}_{2} \mathrm{O}$.

I. 0.5625 g. lost at $105^{\circ}, 0.029$ g., or $5.15 \%$.

2. 5.673 g. lost in racuo (35 days), o.287 g. or $5.06 \%$.

(Calc. for $\mathrm{C}_{30} \mathrm{H}_{49} \mathrm{O}_{4} \mathrm{~K}$. $1.5 \mathrm{H}_{2} \mathrm{O}, 5.00 \%$.)

The salt is soluble in about 36 parts of ethyl alcohol, at $20^{\circ}$, in 2.5 parts methyl alcohol, very slightly in water and ether. On adding water, or dilute alkali, to the saturated methyl alcoholic solution, the salt is precipitated in crystals, which do not re-dissolve on heating, a useful reaction for the recognition of caryophyllin. 
The salt is also precipitated in needles, when alcoholic potassium hydroxide is added to an ether solution of caryophyllin. This test is very delicate, especially if the solution is allowed to stand at a low temperature for some time.

As already noted, the salt is partially hydrolyzed by digestion with water, and it was found that the alkali liberated could be titrated even in the presence of caryophyllin.

Titration.-I.009 g. anhydrous salt was dissolved in $5 \mathrm{cc}$. methyl alcohol, and $25.5 \mathrm{cc}$. 0 . I $N$ sulfuric acid added. The resulting magma was warmed at $90^{\circ}$ till all the alcohol had evaporated, keeping the volume about $50 \mathrm{cc}$. by occasional addition of water. After about three hours, the solution was titrated with aqueous alkali, and the heating continued until permanent neutrality was attained.

Total acid required, 19.19 cc. Acid value, 106.

Another titration gave: Acid value, 105.

Calc. for $\mathrm{K}$ salt of mono-oxy acid, $\mathrm{C}_{37} \mathrm{H}_{37} \mathrm{O}_{3} \mathrm{~K}$. Acid value, II3.4.

Calc. for $\mathrm{K}$ salt of di-oxy acid, $\mathrm{C}_{33} \mathrm{H}_{49} \mathrm{O}_{4} \mathrm{~K}$. Acid value, 109.4.

These results may be considered as evidence in favor of the lactone formula.

In the same manner, a double titration of caryophyllin may be made; determining, first, the alkali absorbed in alcoholic solution, and, second, the equivalent amount liberated by hydrolysis. For example: $1.8135 \mathrm{~g}$. caryophyllin, in $20 \mathrm{cc}$. methyl alcohol, required $7.9 \mathrm{cc} .0 .5 \mathrm{~N} \mathrm{KOH}$ (acid value, I2I.9). The solution was poured into roo $\mathrm{cc}$. hot water, and became alkaline at once; it required, after 48 hours' heating, $7.8 \mathrm{cc} .0 .5 \mathrm{~N}$ acid (acid value, 120.4; calc. acid value, 122.9) for neutralization.

The lactone formula was also indicated by the simple method of weighing the salt obtained from a known weight of caryophyllin. Thus: 2.0085 g. caryophyllin, in $20 \mathrm{cc}$. methyl alcohol, was exactly neutralized by $\mathrm{KOH}$, and the solution evaporated to dryness in vacuo and then at $110^{\circ}$ to constant weight. Dry salt: $2.2500 \mathrm{~g}$. or $1 \mathrm{I} 2.0 \%$ (Calc. for $\mathrm{C}_{30} \mathrm{H}_{47} \mathrm{O}_{3} \mathrm{~K}$, $108.3 \%$; for $\mathrm{C}_{30} \mathrm{H}_{49} \mathrm{O}_{4} \mathrm{~K}$, $112.2 \%$ ).

From alcoholic solutions of the alkaline salt, caryophyllin is precipitated by carbonic anhydride, behaving thus like coumarin and many other lactones. The precipitate, however, generally contains some salt, as is also the case when acetic acid is used. It is, hence, advisable in the preparation of caryophyllin from its salts, to use the stronger mineral acids, and to ensure the complete reaction by sufficient heating. The purity of the precipitated caryophyllin is easily checked by noting its solubility in ether.

\section{Other Salts of Carophyllin.}

Various metallic derivatives are obtained by precipitation from the alcoholic solutions of the alkaline salts of caryophyllin with alcoholic solu- 
tions of the metallic chlorides or acetates. The compounds are generally crystalline and separate slowly from dilute solutions.

The calcium salt is deposited in crystals when alcoholic calcium chloride is added to a $10 \%$ solution of the potassium salt in methyl alcohol. The lead salt is quite insoluble, and is precipitated from a solution containing only $\mathrm{r} \%$ caryophyllin. Normal alcoholic magnesium acetate gives no immediate precipitate with a $0.2 \mathrm{~N}$ solution of caryophyllin, but on standing, the magnesium salt separates in rosets. The zinc salt is amorphous at first, but gradually becomes crystalline. The silver salt is also amorphous, and darkens on exposure to light.

\section{Acetyl Derivatives.}

As already noted, Hjelt obtained an acetate of caryophyllin, but made no analysis. Meyer determined the combined acetic acid in his product, by one hour's saponification with $0.5 \mathrm{~N}$ alcoholic potassium hydroxide. $\mathrm{He}$ found the saponification values: $273.6,290.5,288.4$ (calc. for $\mathrm{C}_{40} \mathrm{H}_{60} \mathrm{O}$ $\left.\left(\mathrm{C}_{2} \mathrm{H}_{3} \mathrm{O}\right)_{4}, 288.6\right)$. These values are a little low for the di-acetate, $\mathrm{C}_{30} \mathrm{H}_{48} \mathrm{O}_{4}(\mathrm{Ac})_{2}$. It seems probable that Meyer's preparation was nearly pure, but, from the writer's experience, the time allowed for saponification was too short to ensure accurate results. The fact that the acetate has a definite acid value also escaped Meyer's attention, and in calculating the total alkali over to acetic acid, he was led to an erroneous formula.

\section{Acetylation.}

Three methods of acetylation were tried: heating with excess of acetic anhydride at $100^{\circ}$; heating with anhydride and sodium acetate at the boiling point of the mixture; and heating the dry potassium salt with anhydride and sodium acetate. In all cases, the products were found to be mixtures, the greater part being easily soluble in ether or acetone, and the rest consisting of a small proportion of crystalline substance very insoluble in ether, acetone or alcohol. Acetylation at $100^{\circ}$ appeared to produce less of the latter compound.

The results of the saponification of the ether-soluble part were at first rather puzzling. The various preparations showed an acid value from Ioo to II5, while the saponification value ranged from 220 to 300 .

It was found that when the acetyl product was crystallized from boiling alcohol, an apparently pure preparation was obtained in long needles, efflorescing on exposure. This uniformly gave figures agreeing with those calculated for a mono-acetate, while products crystallized at a low temperature from ether or acetone, gave much higher saponification values. This indicated an alteration of the primary acetylation product by the hot alcohol, and, in fact, it was found that, on heating the crude acetate with alcohol, ethyl acetate was formed.

The explanation was obvious: the first acetylation product must be 
the di-acetate of the acid of which caryophyllin is the lactone. On heating with alcohol, one acetyl group is split off, forming ethyl acetate and the mono-acetate of carophyllin, a reaction analogous to the production of coumarin from acetyl-coumaric acid.

$$
\mathrm{C}_{29} \mathrm{H}_{47}\left[\begin{array}{l}
\mathrm{O}-\mathrm{CO}-\mathrm{CH}_{3} \\
\mathrm{O}-\mathrm{CO}-\mathrm{CH}_{2} \\
\mathrm{COOH}
\end{array} \rightarrow \mathrm{C}_{29} \mathrm{H}_{47}\left\{\begin{array}{l}
\mathrm{O}-\mathrm{CO}-\mathrm{CH}_{3} \\
\mathrm{O} \\
\mathrm{CO}
\end{array}\right]+\mathrm{HO}-\mathrm{CO}-\mathrm{CH}_{8} .\right.
$$

This conversion may be nicely observed as follows: $0.5 \mathrm{~g}$. di-acetate is dissolved quickly in $20 \mathrm{cc}$. hot absolute alcohol. On cooling, the diacetate crystallizes in plates. If the mixture is again warmed until all the crystals are in solution, on cooling needles appear, and after one or two recrystallizations in this way, a mass of silky needles is obtained, which are the mono-acetate. The presence of ethyl acetate is shown by its characteristic odor.

In other solvents, the same decomposition takes place to a certain degree, depending on the temperature, and whenever acetone or ether solutions of the di-acetate are evaporated, the odor of acetic acid is observed in the residue. The air-dry crystals also gradually give off acetic acid at the ordinary temperature. At $180-190^{\circ}$, the decomposition appears to be complete, and this fact probably explains the statement of Hjelt's, that the acetate melts at $184^{\circ}$.

\section{Di-acetyl Caryophyllinic Acid (Di-acetate).}

Caryophyllin ( 10 g.) was heated with four parts acetic anhydride for six hours at $100^{\circ}$. After about an hour, all crystals were in solution but on further heating the acetate separated out. On cooling, the mass was treated with roo cc. ice water, until all anhydride had decomposed, the crystals were thoroughly washed with dilute sodium carbonate, filtered, and dried in vacuo. Yield, about Io $g$. The crude acetate was then dissolved in about $200 \mathrm{cc}$. ether, filtered from insoluble by-product, and the solution evaporated at a low temperature. The separated crystals were dried in vacuo. Acetone may also be used as solvent, but does not work as well, yielding indistinct crystals. All heating must be avoided.

The product shows a definite acid value, when titrated cold, and on heating with an excess of alkali, a saponification value. For the latter determination, two or three hours' heating at $90-100^{\circ}$ is necessary.

\section{Analyses.}

1. Crystals from acetone, $0.5438 \mathrm{~g}$. required, cold, 1.95 cc. $0.5 N \mathrm{KOH}$. Acid value, 100.2.

I. Crystals from acetone, $0.5438 \mathrm{~g}$. required, hot, 5.75 cc. $0.5 N$ KOH. Sap. value, 296.0 .

2. From acetone, $3.1295 \mathrm{~g}$. required, cold, $12.09 \mathrm{cc} .0 .5 N \mathrm{KOH}$. Acid value, 108.0 .

2. From acetone, $3.1295 \mathrm{~g}$. required, hot, $33.75 \mathrm{cc} .0 .5 \mathrm{~K} \mathrm{KOH}$. Sap. vaiue, 302 . 
3. From ether, I.4855 g. required, cold, $5.35 \mathrm{cc} .0 .5 N \mathrm{KOH}$. Acid value, I00.8.

3. From ether, 1.4855 g. required, hot, $15.80 \mathrm{cc}$. $0.5 \mathrm{~N} \mathrm{KOH}$. Sap. value, 297.7 .

The titrations, after saponification, were performed-as described for caryophyllin. The calculated values for the di-acetate are

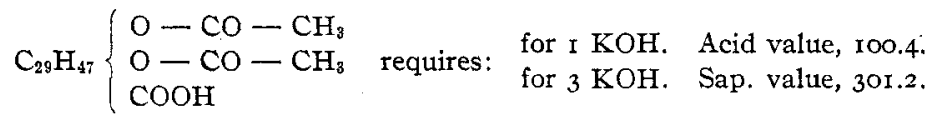

Decomposition on Heating.- $-0.503 \mathrm{~g}$. di-acetate was heated in a small

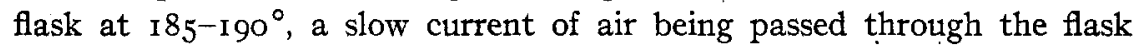
and through two wash-bottles containing 0. I $N \mathrm{KOH}$. After one hour the alkali was titrated, replaced by fresh solution, and the heating continued until no further evolution of acid could be detected. In all, 7.4 cc. alkali were required, equivalent to $0.0444 \mathrm{~g}$. acetic acid, or $8.8 \%$ (calc. I0.7\%).

From acetic anhydride, the di-acetate crystallizes in distinct needles, which fall to a powder on drying. But the product thus obtained retains acetic acid very persistently, even after weeks in vacuo over alkali.

The di-acetate is soluble in about five parts of glacial acetic acid at $100^{\circ}$. In a short time, however, crystals appear and increase in amount, and to obtain permanent solution at $100^{\circ}$, further addition of acetic acid up to twelve parts is necessary. On cooling, a mass of snowy crystals is obtained, which are almost entirely the mono-acetate. This behavior is rather remarkable, and the reaction seems worthy of further study.

The potassium salt of the di-acetate is soluble in three parts of alcohol at $20^{\circ}$; on chilling, it separates in needles. The solution is not stable, and on standing, or, more quickly, on heating, the presence of ethyl acetate becomes apparent, indicating decomposition of the di-acetate. On long heating at $100^{\circ}$, the conversion into the salt of the mono-acetate is complete, the latter compound remaining unaltered under these conditions.

\section{Acetyl-caryophyllin.}

This compound is easily prepared by recrystallization of the crude acetate from 35 to 40 parts of boiling ethyl alcohol. It forms white needles, quickly efflorescing in the air. The dry substance melts at $260-$ $265^{\circ}$ without apparent decomposition.

Determinations of the water of crystallization were not very successful owing to the rapid decomposition of the crystals, even at $0^{\circ}$. No constant weight of the latter could be found, and the loss with material apparently air-dry varied between $\mathrm{I} 3.5$ and $\mathrm{I} 6 \%$. (Calculated for $5 \mathrm{H}_{2} \mathrm{O}, 15 \cdot 3 \%$.)

\section{Analyses.}

I. 1.5815 g: required, cold, $6.02 \mathrm{cc}, 0.5 N \mathrm{KOH}$. Acid value, III.I hot, 12.25 cc. $0.5 N$ KOH. Sap. value, 225.0 
2. 1.9116 g. required, cold, 7.17 cc. $0.5 \mathrm{~N} \mathrm{KOH}$. Acid value, 105.0 hot, 14.7 I cc. $0.5 \mathrm{~N} \mathrm{KOH}$. Sap, value, 215.0

3. I.I $207 \mathrm{~g}$. required, cold, $4.47 \mathrm{cc}$. $0.5 \mathrm{~N} \mathrm{KOH}$. Acid value, III.7 hot, $9.10 \mathrm{cc} .0 .5 \mathrm{~N} \mathrm{KOH}$. Sap. value, 227.0

Calculated for mono-acetate:

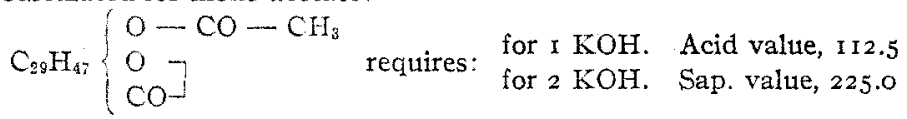

When the dry mono-acetate is mixed with an equal amount of alcohol, it "sets" to a stiff paste, a convenient means to distinguish the two derivatives. They are also differentiated by the behavior of their neutralized alcoholic solutions. Like caryophyllin, the solution of the potassium salt of the mono-acetate becomes alkaline when heated, while the salt of the di-acetate remains neutral to phenolphthalein. This behavior was to be expected, as the mono-acetate is a lactone, and the di-acetate a true acid.

The potassium salt of acetyl caryophyllin is also easily soluble in alcohol, and may be obtained by evaporation of the alcohol solution, mixed with ether, in fine, white needles. When the solution is diluted with water, hydrolysis occurs, and a mixture of acetate and salt is precipitated.

It appeared probable that on heating the alcoholic solutions of the salts of the acetates the following reactions might occur:

$$
\begin{aligned}
& \mathrm{C}_{29} \mathrm{H}_{4 i}\left\{\begin{array}{l}
\mathrm{O}-\mathrm{CO}-\mathrm{CH}_{3} \\
\mathrm{OH} \\
\mathrm{COOK}
\end{array} \rightarrow \mathrm{C}_{29} \mathrm{H}_{47}\left[\begin{array}{l}
\mathrm{OH} \\
\mathrm{O} \\
\mathrm{CO}
\end{array}\right]+\mathrm{KO}-\mathrm{CO}-\mathrm{CH}_{3}\right. \\
& \text { (Salt of mono-acetate.) (Caryophyllin.) }
\end{aligned}
$$

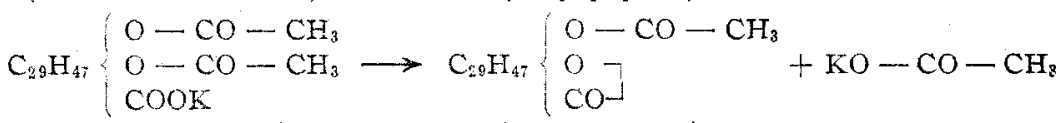

After several hours' heating at $100^{\circ}$, no reaction of this kind, however, was observed in either case. With the di-acetate a partial hydrolysis does take place, as is shown by the formation of ethyl acetate. But, inasmuch as the mono-acetate formed remains in solution as salt, the reaction is probably:

$$
\mathrm{C}_{29} \mathrm{H}_{4}:\left\{\begin{array}{l}
\mathrm{O}-\mathrm{CO}-\mathrm{CH}_{4} \\
\mathrm{O}-\mathrm{CO}-\mathrm{CH}_{8}+\mathrm{C}_{2} \mathrm{H}_{6} \mathrm{OHI}=\mathrm{C}_{29} \mathrm{H}_{47} \\
\mathrm{COOK}
\end{array} \begin{array}{l}
\mathrm{OH} \\
\mathrm{OCOCH} \\
\mathrm{COOK}
\end{array}\right.
$$

If the mono-acetate is heated with three parts of acetic anhydride for one or two hours at $100^{\circ}$, it is converted entirely into the di-acetate, and this is the best method for preparing a pure di-acetate, as the monoacetate is more readily purified than caryophyllin itself.

\section{Polymeric Acetate(?).}

In describing the acetylation of caryophyllin, mention was made of a very insoluble compound, accompanying the di-acetate. This sub- 
stance showed no acid value, and could be purified by washing with alcoholic alkali, which dissolves the di-acetate. On continued heating with. alcoholic potassium hydroxide, it is dissolved, and the solution yields the salt of caryophyllin.

Saponification (four hours at $100^{\circ}$ ), 0.503 g. required $4.015 \mathrm{cc} .0 .5 \mathrm{NKOH}$. Sapon. value, 223.2.

It appears possible that this compound may be a di-lactone:

$$
\begin{gathered}
\mathrm{C}_{28} \mathrm{H}_{37}\left\{\begin{array}{l}
\mathrm{O}-\mathrm{CO}-\mathrm{CH}_{8} \\
\mathrm{O}-\mathrm{CO} \\
\mathrm{CO}-\mathrm{O} \\
\mathrm{CH}_{8}-\mathrm{CO}-\mathrm{O}
\end{array}\right\} \mathrm{C}_{29} \mathrm{H}_{47}
\end{gathered}
$$

with the same saponification value (225) as acetyl caryophyllin. The absence of an acid value would indicate that, for some reason, the lactone rings have a much greater stability than in the case of caryophyllin.

The carbaminic ester and acetyl derivative obtained by Herzog have been already mentioned, but it may be worth while to note that his analyses agree as well, if not better, with the caryophyllin formula proposed by the writer.

\begin{tabular}{|c|c|c|c|c|c|c|}
\hline \multirow[b]{2}{*}{ Found: C } & \multirow[b]{2}{*}{$79.2 \%$} & \multicolumn{3}{|c|}{ 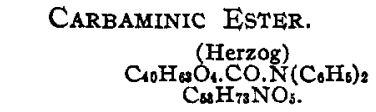 } & \multicolumn{2}{|c|}{$\begin{array}{l}\text { (F. D. D. } \\
\mathrm{C}_{80} \mathrm{H}_{47} \mathrm{O}_{8} \cdot \mathrm{CO} \cdot \mathrm{N}\left(\mathrm{C}_{6} \mathrm{H}_{3}\right)_{2} \\
\mathrm{C}_{43} \mathrm{H}_{37} \mathrm{NO}_{4}\end{array}$} \\
\hline & & & Calc. C & 79.20 & Calc. C & 79.20 \\
\hline $\mathbf{H}$ & 9.3 & & $\mathrm{H}$ & 9.09 & $\mathrm{H}$ & $8.8 \mathrm{I}$ \\
\hline $\mathbf{N}$ & 2.14 & 2.23 & $\mathrm{~N}$ & 1.74 & $\mathbf{N}$ & 2.14 \\
\hline 0 & $\ldots$ & & $\mathrm{O}$ & 9.96 & 0 & 9.85 \\
\hline
\end{tabular}

The nitrogen determinations in particular evidently agree much better with the $\mathrm{C}_{30}$ formula.

Herzog gave the following analysis of his "di-acetate:"

$$
\begin{array}{rrrrrc}
\multicolumn{2}{c}{\text { Di-acetate: }} & \multicolumn{1}{c}{\mathrm{C}_{60} \mathrm{H}_{82} \mathrm{O}_{4}\left(\mathrm{CO}-\mathrm{CH}_{3}\right)_{2} .} & \mathrm{C}_{52} \mathrm{H}_{50} \mathrm{O}_{4} \text { (mono). } & \mathrm{C}_{34} \mathrm{H}_{44} \mathrm{O}_{6} \text { (di). } \\
\text { Found: C } & 76.0 & 76.3 & \text { Calc. } 76.2 & \text { Calc. } 77.04 & 73.06 \\
\mathrm{H} & 9.6 & 9.8 & 9.9 \mathrm{I} & 10.14 & 9.74
\end{array}
$$

His figures indicate that he had in hand a mixture of mono-acetate, and di-acetate.

\section{Caryophyllic Acid.}

The isomerism of caryophyllin with ordinary camphor was noted by the earlier investigators, and, in fact, led Mylius to seek for analogous derivatives. In the hope of obtaining an isomeric camphoric acid, he studied the oxidation of caryophyllin with nitric acid. A well-defined acid was found to be formed when caryophyllin is dissolved in fuming nitric acid, at a moderate temperature. Solution occurred rapidly, and towards the end of the reaction, a crystalline product separated out in large amount. The acid could not be recrystallized from any solvent but nitric acid, and showed no definite melting point. Mylius found the composition to be $\left(\mathrm{C}_{10} \mathrm{H}_{16} \mathrm{O}_{3}\right)_{n}$, and considered $n$ to be probably 2. A 
sodium salt, $\mathrm{Na}_{2}\left(\mathrm{C}_{20} \mathrm{H}_{30} \mathrm{O}_{6}\right)$, and a barium salt, $\mathrm{Ba}\left(\mathrm{C}_{20} \mathrm{H}_{30} \mathrm{O}_{6}\right) . \mathrm{I}^{1} /{ }_{2} \mathrm{H}_{2} \mathrm{O}$, were analyzed.

Meyer (l. c.) also prepared the acid, and determined the acid value. $\mathrm{He}$ found: "o. $1482 \mathrm{~g}$. required $40.75 \mathrm{cc} . n / \mathrm{IO} \mathrm{NaOH}$." These figures correspond to an acid value of 1539 , about five times too large. The amount taken was probably $0.7482 \mathrm{~g}$., giving an acid value, 305 .

By treatment of the acid with acetic anhydride, he obtained an acetyl derivative(?), melting at $202-204^{\circ}$. The acid and its derivatives did not show the Liebermann reaction.

It appeared of interest to obtain, if possible, more information as to the composition and properties of this acid, and its relation to caryophyllin, especially as the available data give no indication of its molecular weight.

Preparation.-The simple method of Mylius was followed. Io g. caryophyllin was gradually added to $50 \mathrm{~g}$. fuming nitric acid (sp. gr. 1.50), the temperature being kept at $15^{-20^{\circ}}$. The operation required about one-half hour, and was accompanied with abundant evolution of nitrous fumes. Towards the end, the mixture suddenly crystallized, forming a stiff paste. After standing one-half hour, the acid was filtered by suction on glass wool, washed with a little nitric acid, and finally with water, and dried in vacuo. The yield amounted to 8-9 $\mathrm{g}$. Without further purification, this product showed an acid value of 306.7 . (I.002 g. required ro. 95 cc. $0.5 \mathrm{~N} \mathrm{KOH}$ (alcoholic).) The calculated acid value for $\mathrm{C}_{10} \mathrm{H}_{16} \mathrm{O}_{3}$ is 304.7 , and this titration obviously gives no information as to the value of " $n$."

It was observed, however, during the titration, that, after about onethird of the total alkali had been added, an abundant crystalline precipitate separated, which redissolved as the titration proceeded, and ultimately disappeared. On subsequent acidification with acetic acid, the precipitate again appeared in large amount. It was evident that this compound must be an acid potassium salt, and its formation offered a welcome means of purifying the acid, and, incidentally, of determining the molecular weight.

\section{Acid Potassium Caryophyllate.}

8 grams crude acid was dissolved in $8 \mathrm{I}$ cc. $0.5 \mathrm{~N}$ alcoholic potassium hydroxide, the solution filtered, and $2 \mathrm{~g}$. pure acetic acid added. On standing, the acid salt was gradually deposited. After twenty-four hours in the cold, the salt was filtered off, washed with alcohol and dried. Weight, $8 \mathrm{~g}$. It was now redissolved in $46 \mathrm{cc} .0 .5 \mathrm{~N}$ alcoholic potassium hydroxide, the solution made up to $80 \mathrm{~g}$. with alcohol, and again precipitated with acetic acid. The final yield of nearly white salt was $6 \mathrm{~g}$. 


\section{Analysis.}

$5.5^{80} \mathrm{~g}$. air-dry salt lost, in vacuo, $0.6 \mathrm{I} 13 \mathrm{~g}$. or $10.95 \%$ :

(Calc. for $\mathrm{C}_{30} \mathrm{H}_{47} \mathrm{O}_{8} \mathrm{~K} .4 \mathrm{H}_{2} \mathrm{O}$, $10.92 \%$.)

r.002 g. dried salt required $6.7 \mathrm{cc} .0 .5 N \mathrm{KOH}$. Acid value, 187.5.

The simplest formula for the acid $\mathrm{C}_{10} \mathrm{H}_{16} \mathrm{O}_{3}$ obviously admits of no acid salt. For $\left(\mathrm{C}_{10} \mathrm{H}_{10} \mathrm{O}_{3}\right)_{2}$, the acid value of $\mathrm{C}_{20} \mathrm{H}_{31} \mathrm{O}_{6} \mathrm{~K}$ is 138 . For $\left(\mathrm{C}_{10} \mathrm{H}_{16} \mathrm{O}_{3}\right)_{3}$, the acid value of the mono-salt $\mathrm{C}_{30} \mathrm{H}_{47} \mathrm{O}_{9} \mathrm{~K}$ is 190 ; for the di-salt $\mathrm{C}_{30} \mathrm{H}_{48} \mathrm{O}_{9} \mathrm{~K}_{2}, 89.2$. It is evident, then, that we are dealing here with a mono-potassium salt of a tribasic acid, $\mathrm{C}_{27} \mathrm{H}_{45} \mathrm{O}_{3}(\mathrm{COOH})_{3}$, a direct oxidation product of caryophyllin, $\mathrm{C}_{30} \mathrm{H}_{48} \mathrm{O}_{3}$, and the properties of the salt are seen to be analogous to some other acid potassium salts of oxyacids, as, e. $g$., tartaric and saccharic acids.

Caryophyllic acid is not very stable, especially in alkaline solution. It appears to lose readily one or more molecules of carbonic anhydride, with formation of lactones, or lactonic acids, which have not been further examined.

\section{Acetylation of Caryophyllic Acid.}

If the constitution of caryophyllic acid be correctly represented by the partial structural formula $\mathrm{C}_{27} \mathrm{H}_{45} \mathrm{O}_{3}(\mathrm{COOH})_{3}$, there remain three oxygen atoms, whose functions are to be determined, and, as in the case of caryophyllin, the results of the acetylation seemed likely to afford some light on this point.

When caryophyllic acid is treated with three parts of acetic anhydride, without heating, the mixture soon solidifies, indicating a reaction of some kind. Heated for an hour or two, at $100^{\circ}$, a clear solution is obtained, which, on cooling, deposits a mass of crystals. These are very slightly soluble in alcohol, or ether, and were purified by thorough washing with methyl alcohol. The compound thus obtained melted at $210-213^{\circ}$, with slight decomposition, and appeared to be the substance described by Meyer. By titration and saponification, the following values were found:

I. I.0055 g. required, cold, $8.06 \mathrm{cc} .0 .5 N \mathrm{KOH}$. Acid value, 224.5 hot, I $1.60 \mathrm{cc}$. $0.5 \mathrm{~N} \mathrm{KOH}$. Sap. value, 323.0

2. $2.490 \mathrm{~g}$. required, cold, $19.15 \mathrm{cc} .0 .5 \mathrm{~N} \mathrm{KOH}$. Acid value, 215.3 hot, 28.10 cc. $0.5 N \mathrm{KOH}$. Sap. value, 316.0

It will be noticed that these values are much lower than would be expected, and are about in the proportion of 2 to 3 , whereas normal acetyl derivatives of caryophyllic acid would show ratios of these values of 3 to 4 , 3 to 5 , or 3 to 6 . Thus:

Mono-acetyl caryophyllic acid, Acid value, 283.1 ; sapon. value, 377.4

Di-acetyl caryophyllic acid. Acid value, 264.4; sapon value, 440.6

Tri-acetyl caryophyllic acid. Acid value, 248.1; sapon. value, 496.2

The values actually obtained indicate that this compound is the result of some secondary reaction. If we assume that in the acetylation, one 
molecule of carbonic anhydride is eliminated, which is not unprecedented, and that the remaining two carboxyl groups form lactone rings, with loss of two molecules of water, we arrive at the formula $\mathrm{C}_{31} \mathrm{H}_{46} \mathrm{O}_{6}$ for the compound, an acetyl di-lactone, with the calculated acid value 2I8.I, and saponification value, 327.2 .

In agreement with this hypothesis, the compound was found to behave like a lactone, and the product of its hydrolysis was not the original caryophyllic acid, but apparently a new acid, or a mixture of acid and lactones, which so far we have not succeeded in purifying.

On acidifying the alkaline solution, a mixture of oil and crystals was obtained, which gradually entirely solidified. It is partly soluble in alkaline carbonate solution, and entirely in warm dilute hydroxide, and is reprecipitated partially by carbonic anhydride. Attempts at recrystallization from alcohol and acetone were without result. The product which had completely solidified on long standing was dried at $60^{\circ}$, and on titration showed an acid value of 232 . (Calc. for the acid: $\mathrm{C}_{27} \mathrm{H}_{43}(\mathrm{COOH})_{2}(\mathrm{OH})_{3}, 220.7$.)

The acet-lactone results apparently from the following reaction:

$$
\mathrm{C}_{27} \mathrm{H}_{42}\left[\begin{array}{l}
\mathrm{OH} \\
\mathrm{COOH} \\
\mathrm{OH} \\
\mathrm{COOH} \\
\mathrm{OH} \\
\mathrm{COOH}
\end{array}+3 \overline{\mathrm{A}}_{2} \mathrm{O}=\mathrm{C}_{27} \mathrm{H}_{42}\left[\begin{array}{l}
\mathrm{OA} \\
\mathrm{CO}_{7} \\
\mathrm{O} \\
\mathrm{CO} \\
\mathrm{O} \\
\mathrm{H}
\end{array}\right]+\mathrm{CO}_{2}+5 \mathrm{HO} \overline{\mathrm{A}}\right.
$$

according to which caryophyllic acid may be formulated as a tri-oxy tricarboxylic acid.

If the acetylation of caryophyllic acid is made at room temperature, after a few days' standing, the acid is completely dissolved. From this solution, a crystalline product is obtained which is readily soluble in alcohol. The solution, however, soon shows the presence of ethyl acetate, indicating a decomposition of some higher acetylation product.

Another interesting reaction of caryophyllic acid was observed. If the neutral alcoholic solution obtained by titrating the acid potassium salt be allowed to stand a few days in a closed flask, well-defined crystals are slowly deposited, the solution becoming slightly acid. After a month or so, with occasional neutralization, the greater part of the salt has separated. The crystals are nearly insoluble in alcohol, but readily in a small amount of water, forming a very viscid solution. On dilution with much water, alkali is liberated, and an insoluble compound slowly precipitated. From the aqueous solution, hydrochloric or acetic acid throws down a bulky amorphous product, which, with alcoholic potassium hydroxide, is reconverted into the insoluble crystalline salt.

The latter is evidently the salt of a lactone: the lactone is easily soluble in alcoliol, but shows no tendency to crystallize. On titration, an acid value of 238 was found (caled. for $\mathrm{C}_{29} \mathrm{H}_{44} \mathrm{O}_{5}, 237.2$ ). 
On acetylation, this lactone was converted into a very insoluble compound, which crystallized from about Ioo parts boiling alcohol in silky needles, melting at $219^{\circ}$ (corr.). No definite titration results could be obtained, the compound dissolving very slowly in alkali, in fact, behaving like the more stable $\gamma$ lactones. It was evidently different from the acet-lactone already described.

\section{Urson.}

Urson, a crystalline substance occurring with arbutin in the leaves of the bearberry (Arctostaphylos Uva Ursi), was first described by Trommsdorf. ${ }^{1}$ It was obtained by treating the alcoholic extract of the leaves with ether, and recrystallizing the residue from alcohol. The product consisted of silky needles, odorless and tasteless, insoluble in water, dilute acids or alkalies. It boiled and sublimed apparently without decomposition, and dissolved readily in fuming nitric acid. From the latter solution, a white substance was precipitated on dilution with water. Trommsdorf assigned to urson the formula $\left(\mathrm{C}_{10} \mathrm{H}_{16} \mathrm{O}\right)_{n}$. Hlasiwetz ${ }^{2}$ and Rochleder ${ }^{3}$ also report analyses of urson, the former finding the composition $\left(\mathrm{C}_{10} \mathrm{H}_{17} \mathrm{O}\right)_{n}$, the latter agreeing with Trommsdorf.

The first thorough examination of the substance is due to Gint $1,{ }^{4}$ who studied a preparation by Merck, and the striking similarity between urson and caryophyllin is shown in the following tabulation of his results, in comparison with those obtained by the writer and others for caryophyllin:

URson.

M. p. $264-266^{\circ}$.

Composition: $\left(\mathrm{C}_{10} \mathrm{H}_{16} \mathrm{O}\right)_{n}$.

Mol. wt. $n=3$ (in phenol).

Crystals contain $2 \mathrm{H}_{2} \mathrm{O}$.

Not sublimable (?). needles.

With acetone, swells up, but is only Same behavior. slightly soluble.

Shows Liebermann-Salkowski cholesterol Same behavior. reaction.

On evaporation with $\mathrm{FeCl}_{3}$ and $\mathrm{HCl}$ Same behavior. residue is colored intense blue.

No oxime or phenyl-hydrazone.

No methoxyl group.

Acetate, fine needles, m. p. $264^{\circ}$. Cont. $5 \mathrm{H}_{2} \mathrm{O}$.

Benzoate, m. p. $214^{\circ}$ (not obtained in crystals).

${ }^{1}$ Arch. Pharm., 80, 273 (1854).

2 Sitzb. Akad. Wiss. Wien, 16, 293 (1855).

${ }^{3}$ Ibid., 53, 5 19 (1866).

4 Monatsh., 14, 255 (1893).
CARYophyllin.

$295^{\circ}$ (Meyer), $310^{\circ}$ (F. D. D.).

$\left(\mathrm{C}_{10} \mathrm{H}_{18} \mathrm{O}\right)_{n}$ (Mylius, Meyer and others).

$n=4$ (Meyer?), $n=3$ (F. D. D.).

$2 \mathrm{H}_{2} \mathrm{O}$ (F. D. D.).

Sublimable.

Needles.

Same behavior.

?

Acetate, needles, m. p. $268-271^{\circ}, 255^{\circ}$

(Herzog), (F. D. D.), $5 \mathrm{H}_{2} \mathrm{O}$ (?) (F. D. D.).

Benzoate, m. p. $185^{\circ}$ (Herzog). 
In spite of certain differences in melting points, there is evident here a remarkable resemblance between these two substances. Yet the available data are hardly sufficient to determine their possible identity or isomerism, and a further careful comparison of urson and caryophyllin appeared necessary.

Two samples of urson were studied: one from Merck, "Urson puriss.," the other prepared from bearberry leaves by the method already described for the purification of caryophyllin.

\section{Preparation of Urson.}

$200 \mathrm{~g}$. of commercial Uva Ursi was throughly dried, pulverized, and mixed with one liter of methyl alcohol and 150 cc. of $2 \mathrm{~N}$ alcoholic potassium hydroxide, and allowed to stand several days with frequent shaking. The mixture was then filtered, and the residue washed clean with about 300 cc. of methyl alcohol. The combined filtrate and washings were acidified with acetic acid and concentrated to about $300 \mathrm{cc}$. On cooling, greenish crystals, amounting to about $4 \mathrm{~g}$., were deposited, and on further concentrating, a more impure product $(7 \mathrm{~g}$.). By recrystallization from alcohol, with bone black, $5 \mathrm{~g}$. of white crystals were obtained.

In general chemical behavior, 11rson appeared to be very like caryophyllin, yet certain peculiarities in solubility, and habit of crystallization, became evident. Especially noticeable was the tendency to gelatinize from impure solutions, a behavior never, in the writer's experience, observed in the case of caryophyllin.

The Merck preparation consisted of distinct white needles, which slowly lost weight in the air, more rapidly in the desiccator, the dehydration being complete at $105^{-110^{\circ}}$.

I.023 g. lost at $110^{\circ}, 0.074$ g., or $7.24 \%$. (Calc. for $\mathrm{C}_{80} \mathrm{H}_{48} \mathrm{O}_{3.2} \mathrm{H}_{2} \mathrm{O}, 7.3 \mathrm{I} \%$.)

The dry compound melted at about $285^{\circ}$ (corr.), apparently with slight decomposition, and in vacuum tube at $280^{\circ}$, sublimed in well-formed crystals.

The solubility of urson in alcohol and ether is almost the same as that of caryophyllin. The alcoholic solution is neutral to litmus.

Like caryophyllin, in alcoholic solution, urson neutralizes alkali immediately, and may be titrated with accuracy, a fact which apparently escaped the notice of Gintl. The acid value obtained is exactly that found by the writer for caryophyllin.

0.949 g. required $4.16 \mathrm{cc}$. $0.5 \mathrm{~N} \mathrm{KOH}$. Acid value, 122.7. (Calc. for $\mathrm{C}_{80} \mathrm{H}_{48} \mathrm{O}_{3}$, 122.9.)

The Merck preparation was not perfectly soluble on titration, and the solution on standing deposited a minute amount of gray, amorphous matter, evidently a slight impurity.

But, unlike caryophyllin, no crystalline potassium salt separated from 
the neutral alcoholic solution. On evaporation, a crystalline residue was left, which was easily soluble in ethyl alcohol.

This difference in solubility of the potassium salts is so far the most characteristic distinction between caryophyllin and urson, and, in fact, may be utilized to effect an approximate separation of the two compounds. For example, if I $\mathrm{g}$. of the potassium salt of caryophyllin be dissolved in $4 \mathrm{cc}$. of methyl alcohol, slightly warmed, and $2 \mathrm{cc}$. water slowly added, the salt separates quickly in well-defined crystals, which do not redissolve on heating. A similar solution of the urson salt remains clear when an equal volume of water is added, and on further dilution, becomes alkaline, with gradual separation of urson, owing to hydrolysis.

When alcoholic potassium hydroxide is added to the ether solution of caryophyllin, the potassium salt separates in crystals of characteristic form. From a similar solution of urson, very fine needles are gradually precipitated, which disappear immediately if the ether is allowed to evaporate, owing to their much greater solubility in the residual alcoholic liquor.

\section{Separation of Caryophyllin and Urson.}

I. $0.845 \mathrm{~g}$. dry caryophyllin and $0.840 \mathrm{~g}$. dry urson were dissolved in the necessary amount of $0.5 \mathrm{~N}$ methyl alcoholic potassium hydroxide, and $3 \mathrm{cc}$. $0.5 \mathrm{~N}$ aqueous potassium hydroxide added. The precipitate formed was dissolved by slight heating, and the solution allowed to crystallize at $0^{\circ}$ for 24 hours. The caryophyllin salt was then filtered off, washed with $5 \mathrm{cc}$. of $70 \%$ alcohol and dried. Weight, $0.745 \mathrm{~g}$. This was dissolved in $4 \mathrm{cc}$. methyl alcohol, diluted with water to $50 \mathrm{cc}$, and acidified with hydrochloric acid. The caryophyllin precipitate, after filtering, washing and drying, amounted to $0.685 \mathrm{~g}$. From the first alkaline mother liquor, the urson was recovered similarly, and weighed $0.960 \mathrm{~g}$.

The caryophyllin, dissolved in $3 \mathrm{cc}$. $0.5 \mathrm{~N}$ methyl alcoholic potassium hydroxide, gave an immediate abundant precipitate on adding aqueous potassium hydroxide. The urson was entirely soluble in a mixture of 3 cc. $0.5 \mathrm{~N}$ methyl alcoholic potassium hydroxide, and $3 \mathrm{cc} .0 .5 \mathrm{~N}$ aqueous potassium hydroxide. On standing, however, for several days in the cold, crystals separated, from which by washing with $70 \%$ alcohol, a further amount of caryophyllin salt (0.205 g.) was obtained.

2. $0.5085 \mathrm{~g}$. caryophyllin and $0.5012 \mathrm{~g}$. urson were heated at $80^{\circ}$ several hours with $5 \mathrm{cc}$. $0.5 \mathrm{~N}$ ethyl alcoholic potassium hydroxide then let stand two days at $0^{\circ}$. The precipitate, washed with $70 \%$ alcohol and dried, weighed $0.536 \mathrm{~g}$. From this, $0.467 \mathrm{~g}$. caryophyllin was recovered. From the mother liquor and washings, $0.536 \mathrm{~g}$. urson.

The experiments show that if present in large amount, caryophyllin can be separated in reasonable purity from urson. The latter cannot, however, be completely freed from small amounts of caryophyllin. 
A comparison was also made of the rotations of the potassium salts of caryophyllin and urson.

I. Caryophyllin, dry, $0.8478 \mathrm{~g}$. dissolved in q. s. methyl alcoholic potassium hydroxide, and made to Io cc. +6.45 at $24.5^{\circ}$

$$
\begin{aligned}
{[\alpha]_{D} } & =+76.08^{\circ} \text { (for } \mathrm{C} \text {.) } \\
& +67.76^{\circ} \text { (for } \mathrm{K} \text { salt) }
\end{aligned}
$$

2. C. 0.9997 g. similarly in $10 \mathrm{cc}$. +7.50 at $30.7^{\circ}$

$$
\begin{aligned}
{[\alpha]_{D} } & \left.+75.02^{\circ} \text { (for } \mathrm{C} .\right) \\
& +66.82^{\circ} \text { (for } \mathrm{K} \text { salt) }
\end{aligned}
$$

3. Urson, dry, r. ro g g. similarly in ro cc. +7.15 at $24.5^{\circ}$

$$
[\alpha]_{\mathrm{D}}=+64.94^{\circ} \text { (for U.) }
$$

$+57.84^{\circ}$ (for $\mathrm{K}$ salt)

4. U. $1.0313 \mathrm{~g}$. similarly in $10 \mathrm{cc}$. +6.60 at $31.8^{\circ}$

$$
[\alpha]_{D}=+63.99^{\circ} \text { (for U.) }
$$

$+57.00^{\circ}$ (for K salt)

\begin{tabular}{|c|c|c|}
\hline Extinction. & $\begin{array}{l}\text { Caryophyllin. } \\
\text { Parallel, to } 15^{\circ}\end{array}$ & $\begin{array}{l}\text { Urson. } \\
\text { Parallel }\end{array}$ \\
\hline Elongation. & Negative & Positive \\
\hline Retardation, in wave-lengths. & $4-7$ & $1 / 4-I$ \\
\hline Birefringence, from assumed thickness. & $0.02-0.06$ & 0.003 \\
\hline 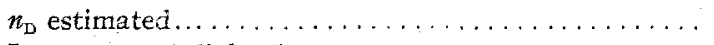 & $1.54^{-1} .60$ & I. $53-$ I. 54 \\
\hline In convergent light shows $\ldots \ldots \ldots \ldots \ldots$ & Optic axis & Acute bisectrix \\
\hline$\ldots \ldots \ldots \ldots \ldots \ldots \ldots \ldots$ & $60-90^{\circ}$ & $22-28^{\circ}$ \\
\hline Crystals are probably $\ldots \ldots \ldots \ldots \ldots \ldots$ & Monoclinic & Orthorhombic \\
\hline
\end{tabular}

When caryophyllin and urson are allowed to crystallize very slowly from dilute alcoholic solutions, long, prismatic needles are obtained, which can hardly be distinguished in ordinary light under the microscope. The writer is indebted to Mr. J. P. Wintringham for a more detailed examination, as follows:

The compounds may be distinguished by observation of the refractive index, the sign of the elongation, or the interference colors.

\section{Other Salts of Urson.}

The lead salt is precipitated on the addition of alcoholic lead acetate to a $10 \%$ alkaline urson solution. It appears to be somewhat more soluble than the caryophyllin salt. Normal alcoholic zine acetate causes no immediate precipitate with a $0.2 \mathrm{~N}$ urson solution, but after a short time the mixture gelatinizes, and on long standing, becomes filled with crystalline rosets. The magnesium salt is readily soluble in alcohol.

I g. urson is readily soluble in Io cc. $0.5 \mathrm{~N}$ alcoholic ammonia; on standing, a crystalline mass is formed which may be an ammonium salt. (Caryophyllin is only slightly soluble in alcoholic ammonia.)

\section{Acetylation.}

For a further comparison of caryophyllin and urson, parallel acetylations were made.

$5 \mathrm{~g}$. and $5 \mathrm{~g}$. acetic anhydride, on water bath three hours. 
Caryophyllin.

After one hour, all in solution; then crystals form, and increase in amount: on cooling, a semi-solid mass.

Crystals filtered and dried in vacuo.

On titration, cold, no crystalline salt separates.

From solution, after saponification $\mathrm{K}$ salt crystallizes.

Caryophyllin only slightly soluble in alcoholic $\mathrm{KOH}$.
Urson.

After one-half hour, all in solution.

On cooling, no crystals after 48 hours. On adding a little alcohol and shaking, crystals ( 3 g.) were deposited. From mother liquor, by addition of water, $1.5 \mathrm{~g}$.

Crystals dried in vacuo.

Titration, I.06 g. required 4.21 cc. $0.5 \mathrm{~N}$ $\mathrm{KOH}$. Acid value, x Io.9 (çalc. IOO. I).

Potassium salt crystallizes from neutral solution.

$0.5 N \mathrm{KOH}$ added to $\mathrm{I}_{5} \mathrm{cc}$. total, and saponified three hours. Total $\mathrm{KOH}$, Ir.82 cc.; sapon. value, 312 (calc. $300.3)$.

The compound is evidently di-acetate, containing a little acetic acid.

No salt separates on standing.

On adding $30 \mathrm{cc}$. water, the solution becomes alkaline, and urson is precipitated. The mixture was evaporated to remove alcohol, keeping constant volume with water. Titrated, required $3.8 \mathrm{cc}$. $0.5 N \mathrm{HCl}$. Acid value, I06.4 (calc. 100.I).

Residual urson, easily soluble in alcoholic $\mathrm{KOH}$.

Decomposition of Di-acetates.

2 g. required 44 g. $95 \%$ alcohol at $90^{\circ}$, for solution.

Recrystallized twice, yielded very fine, bulky needles.

(Mono-acetate.)

Dried in vacuo.
2 g. in 25 g. $95 \%$ alcohol dissolved completely in a few minutes, at $90^{\circ}$. On cooling, transparent prisms separated. Recrystallized twice deposited a mass of needles, not so silky, nor so bulky as the caryophyllin acetate.

Dried in vacuo.

\section{Titration.}

1.016 g. required $4.12 \mathrm{cc}, 0.5 N \mathrm{KOH}$. Acid value, II 3.5 (calc. II2.5).

All soluble except a minute white sediment.

Added Io cc. $0.5 N \mathrm{KOH}$ and saponified 2.5 hours.

Total alkali, $8.23 \mathrm{cc}$.

Sapon. value, 226.5 (calc. 225).

$\mathrm{K}$ salt of caryophyllin crystallizes out on standing. $x .026 \mathrm{~g}$. required $4.14 \mathrm{cc} .0 .5 N \mathrm{KOH}$. Acid value, I 12.9 (calc. I 22.5 ).

$\mathrm{K}$ salt crystallizes out.

Same as above.

Total alkali, $8.49 \mathrm{cc}$.

Sapon. value, 23 1.6 (calc. 225).

No crystals deposited.

The compound was evidently a monoacetate, containing a little di-acetate. 


\section{Urson Di-acetate (Di-acetyl Ursonic Acid).}

The di-acetate resembles the corresponding caryophyllin derivative in chemical properties, but is in general more soluble, and apparently less stable. Decomposition to the mono-acetate occurs so readily that it was found impossible to prepare a pure compound by recrystallization from ether or acetone. On heating, it gives off acetic acid at about $135^{\circ}$, and then melts at about $165^{\circ}$.

Decomposition on Heating.- $0.2185 \mathrm{~g}$. in open tube, began to give off acetic acid at $\mathrm{I} 35^{\circ}$, and melted completely to a transparent glass at $165^{\circ}$. Loss in weight, $3.5 \%$. After four hours' heating at $190-200^{\circ}$, the loss was $8.5 \%$. No further loss occurred on continued heating, and on cooling, a crystalline mass of mono-acetate remained (calc. loss, II.7\%).

Like the caryophyllin compound, urson di-acetate is converted into mono-acetate when recrystallized from acetic acid.

When titrated alone with $0.5 \mathrm{~N}$ alcoholic potassium hydroxide, it dissolves at first, but the mixture soon solidifies, owing to the separation of the slightly soluble salt, and the formation of ethyl acetate is immediately manifest.

\section{Urson Mono-acetate (Acetyl-urson).}

From alcoholic solution, this compound separates in plates and prisms, quite different in appearance from the caryophyllin compound. The crystals are comparatively stable in the air, and contain $5 \mathrm{H}_{2} \mathrm{O}$ (agreeing with Gintl, l. c.).

I.2722 g. lost $0.1915 \mathrm{~g}$. or $15.1 \%$ (calc, for $5 \mathrm{H}_{2} \mathrm{O}, 15.3 \%$ ).

The alcoholic solution, at $25^{\circ}$, contains $\mathrm{r} .4 \%$ dry acetate.

On titration, the mono-acetate dissolves readily, but on standing, the potassium salt crystallizes out, and, like the caryophyllin derivative, this salt is stable in solution at $100^{\circ}$.

\section{Ursonilic Acid(?).}

As already noted, Trommsdorf $(l, c$.) observed the behavior of urson with nitric acid. In the hope of obtaining an acid isomeric with caryophyllic acid, the writer treated urson with fuming nitric acid in the manner described above. The oxidation proceeded as in the case of caryophyllin but no crystalline product separated. On dilution, an amorphous substance was obtained, from which no crystalline potassium salt could be prepared, and for lack of a means of purification of the crude acid, the examination was discontinued.

\section{Color Reactions.}

Caryophyllin and urson both show the Liebermann-Salkowski cholesterol reaction, as noted by Meyer and Gintl. For example, if $0.020 \mathrm{~g}$. caryophyllin be dissolved in so cc. acetic anhydride, and ro drops sulfuric acid added, the solution assumes, in a few minutes, a purple color, with 
strong green fluorescence. On standing, the color deepens and passes through green to a greenish yellow. Urson behaves similarly.

This reaction is also shown by the amyrin compounds of Vesterberg, ${ }^{1}$ and a comparison of the formulas indicates the possibility of some interesting relationships.

$$
\begin{aligned}
& \text { Cholesterol........ } \mathrm{C}_{26} \mathrm{H}_{48} . \mathrm{OH} \text { or: } \mathrm{C}_{26} \mathrm{H}_{40}\left\{\begin{array}{l}
\mathrm{H} \\
\mathrm{H} \\
\mathrm{H} \\
\mathrm{OH}
\end{array}\right. \\
& \text { Amyrin........... } \mathrm{C}_{30} \mathrm{H}_{48} . \mathrm{OH} \text { or: } \mathrm{C}_{26} \mathrm{H}_{40}\left\{\begin{array}{l}
\mathrm{H} \\
\mathrm{OH} \\
\mathrm{CH}_{8} \\
\mathrm{C}_{3} \mathrm{H}_{6}
\end{array}\right. \\
& \text { Caryophyllin...... } \mathrm{C}_{30} \mathrm{H}_{48} \mathrm{O}_{3} \text { or: } \quad \mathrm{C}_{26} \mathrm{H}_{40}\left\{\begin{array}{l}
\mathrm{OH} \\
\mathrm{O} \\
\mathrm{CO} \\
\mathrm{C}_{3} \mathrm{H}_{7}
\end{array}\right.
\end{aligned}
$$

No explanation of this color reaction has as yet been offered. It has, however, been shown, in this laboratory, ${ }^{2}$ that the sesquiterpene, gurjunene, when treated with the Liebermann reagent, is oxidized to the remarkable blue hydrocarbon, azulene; $\mathrm{C}_{15} \mathrm{H}_{18}$, and it appears not unlikely that a similar reaction may occur in the cases of these more complex molecules, which may be considered as derivatives of a tri-terpene nucleus.

It is also perhaps interesting to note the natural occurrence of a series

\begin{tabular}{|c|c|c|}
\hline Terpenes, $\mathrm{C}_{10} \mathrm{H}_{18} \ldots$ & $\mathrm{C}_{10} \mathrm{H}_{12} \mathrm{O}_{4}$ & Cantharidin \\
\hline & $\mathrm{C}_{10} \mathrm{H}_{8} \mathrm{O}_{4}$ & Anemonin \\
\hline Sesquiterpenes, $\mathrm{C}_{1 b} \mathrm{H}_{24} \ldots \ldots \ldots \ldots \ldots$ & $\mathrm{C}_{15} \mathrm{H}_{18} \mathrm{O}_{8}$ & Santonin \\
\hline & $\mathrm{C}_{15} \mathrm{H}_{18} \mathrm{O}_{4}$ & Artemisin \\
\hline & $\mathrm{C}_{16} \mathrm{H}_{20} \mathrm{O}_{2}$ & Alantolacetone \\
\hline & $\mathrm{C}_{15} \mathrm{H}_{16} \mathrm{O}_{6}$ & Picrotoxinin \\
\hline Diterpenes, $\mathrm{C}_{20} \mathrm{H}_{3}$ & $\mathrm{C}_{40} \mathrm{H}_{30} \mathrm{O}_{2}$ & Abietic "acid"'s \\
\hline & $\mathrm{C}_{20} \mathrm{H}_{28} \mathrm{O}_{3}$ & Illuric "aćid"3 \\
\hline Triterpenes, $\mathrm{C}_{30} \mathrm{H}$ & $\mathrm{C}_{30} \mathrm{H}_{48} \mathrm{O}_{3}$ & Caryophyllin, Urson \\
\hline & $\mathrm{C}_{30} \mathrm{H}_{48} \mathrm{O}_{6}$ & Digitogenin (?) \\
\hline
\end{tabular}
of lactones, corresponding to and possibly derived from the various terpene series.

\section{Summary.}

The comparison of caryophyllin and urson has thus far brought to light the extraordinary similarity of these compounds. In strictly chemical properties, no differences have been observed. But the variations in physical properties, summarized below, appear to the writer sufficient

1 Ber., 20, 1242 (1887); 23, 3186 (1890); 24, 3834 (1891).

${ }^{2}$ Sherndal, THIS JoURNaL, 37, 167, 1537 (1915).

${ }^{3}$ From the results of the examination of these compounds by the writer, they should probably be classified as lactones. 
to warrant the assumption that they are isomers of very similar structure.

$$
\text { Caryophyllin. }
$$

$\mathrm{K}$ salt, slightly soluble in alcohol.

$\mathrm{K}$ salt of di-acetate, easily soluble in alcohol.

$\mathrm{K}$ salt of mono-acetate; easily soluble in alcohol.

Mono-acetate, $5 \mathrm{H}_{2} \mathrm{O}$ (?), cryst. in fine needles, efforescent, alcoholic solution at $25^{\circ}$, contains $0.27 \%$.

Slightly soluble in alcoholic $\mathrm{NH}_{3}$.

$\mathrm{Mg}$ salt, slightly soluble in alcohol.
Urson.

$K$ salt, very soluble in alcohol.

$K$ salt of di-acetate, slightly soluble in alcohol.

$\mathrm{K}$ salt of mono-acetate, slightly soluble in alcohol.

Mono-acetate, $5 \mathrm{H}_{2} \mathrm{O}$, cryst. in transparent prisms, stable in air, alcoholic solution at $25^{\circ}$, contains $1.4 \%$.

Easily soluble in alcoholic $\mathrm{NH}_{3}$.

$\mathrm{Mg}$. salt, easily soluble in alcohol.

The evidence so far gathered seems also to confirm the lactone structure assumed for these compounds. The neutrality in alcoholic solution, the tendency of the salts to hydrolyze, the precipitation by carbonic anhydride, the composition of the potassium salt, the preparation of two acetates, are in harmony with this formula. It must be noted, however, that the practically instantaneous neutralization of alkali in alcoholic solution, and the opening of the lactone ring on acetylation, are reactions not generally exhibited by the better known lactones. The writer has examined a number of accessible lactones, such as phenyl-butyrolactone, phenyl-paraconic acid, methyl heptanolid, terpenylic acid, phthalid, and santonin, and in all cases found that the neutralization was a reaction requiring considerable time at ordinary temperatures. These, however, are all $\gamma$ lactones, the most stable variety. A study of some other types is in progress, and the results are reserved for a future communication.

\section{Compounds Possibly Identical with Caryophyllin or Urson.}

Gentiol was obtained by Goldschmiedt and Jahoda, ${ }^{1}$ from the leaves of Genitina verna, as crystalline needles, melting at $215^{-219^{\circ}}$. The composition was determined as $\left(\mathrm{Cl}_{0} \mathrm{H}_{16} \mathrm{O}\right)_{n}$, and a molecular-weight determination in phenol solution indicated that $n=3$. An amorphous acetate, melting at $175^{-1} 80^{\circ}$, was prepared, which, from the elementary analysis, appeared to be a tri-acetate.

The fact that "gentiol" separates in gelatinous form from alcoholic solution, indicates a possible identity with urson, and the low melting points observed must be due to impurity. Gentiol also shows the Liebermann cholesterol reaction, and the color reaction with ferric chloride, as noted by Gintl (l. c.).

Lactucon, from Lactuca altissima by Franchimont, ${ }^{2}$ crystallized from alcohol, with melting point, $296^{\circ}$. Acetylation gave a product melting at

1 Monatsh., I2, 480 ( $189 \mathrm{x}$ ).

2Ber., I2, Io (1879). 
$295^{-296^{\circ}}$ (not analyzed). The analyses of lactucon, however, indicated the formula $\left(\mathrm{C}_{14} \mathrm{H}_{24} \mathrm{O}\right)_{n}$.

Vitin was isolated by Seifert ${ }^{1}$ from the skins of American grapes. It forms acicular crystals, difficultly soluble in alcohol, melting at $250-255^{\circ}$. Analysis indicated $\left(\mathrm{C}_{10} \mathrm{H}_{16} \mathrm{O}\right)_{n}$; from the observed molecular weight in phenol, $n=2$ (?). A mono-acetate, $\mathrm{C}_{20} \mathrm{H}_{31} \mathrm{O} . \mathrm{OAc}($ ?), was prepared, slightly soluble in alcohol, and melting at $239^{\circ}$.

Seifert described a number of salts of vitin, but observed that titration led to "no definite result:" possibly because irreconcilable with the assumed formula $\left(\mathrm{C}_{10} \mathrm{H}_{16} \mathrm{O}\right)_{2}$. The ammonium salt, needles, slightly soluble in alcohol, and easily dissociated; the calcium salt, by precipitating a solution of the potassium salt with calcium chloride solution; long, fine needles, with the composition $\mathrm{Ca}\left(\mathrm{C}_{20} \mathrm{H}_{31} \mathrm{O}_{2}\right)_{2} .2 \mathrm{C}_{20} \mathrm{H}_{32} \mathrm{O}_{2}$. The copper and lead salts had apparently a similar composition. The solubility of the potassium salt indicates that vitin is probably identical with urson, and the composition of the other salts is explained by the fact that they were precipitated from more or less aqueous solutions, conditions under which, as has been shown, the salts of urson and caryophyllin are largely dissociated.

Vitin was found to be strongly dextro-rotatory: in alcoholic solution, containing $0.4 \mathrm{I} 75 \%,[\alpha]_{D}= \pm 59.87^{\circ}$ (v. urson). It also shows the Liebermann and ferric chloride colorations.

Oenocarpol.-Etard ${ }^{2}$ isolated from grape skins a palmitic ester (m. p. $272^{\circ}$ ) of an alcohol, $\mathrm{C}_{26} \mathrm{H}_{42} \mathrm{O}_{3} \cdot \mathrm{H}_{2} \mathrm{O}$. The latter crystallized from ether in long needles, melting at $304^{\circ} . \alpha_{D}$ in ether $=+60.8^{\circ}$. The acetyl derivative melted at $215^{\circ}$. The alcohol, when distilled at $405^{\circ}$, decomposed, yielding water and a thick oil, $\mathrm{C}_{26} \mathrm{H}_{36}$, with strong odor, which combined with water to a hydrate, $\left(\mathrm{C}_{26} \mathrm{H}_{36}\right)_{2} \mathrm{H}_{2} \mathrm{O}$, (m. p. $75^{\circ}$ ). The potassium salt was obtained in needles, $\mathrm{C}_{26} \mathrm{H}_{41}(\mathrm{OH})_{4} \mathrm{OK}$; also silver and lead compounds. When oxidized by chromic acid, an amorphous acid, $\mathrm{C}_{26} \mathrm{H}_{42} \mathrm{O}_{5}$, was obtained.

Oenocarpol appears to be identical with vitin, but Etard's analyses would seem to require confirmation.

BAyONNE, N. J.

1 Monatsh., 14, 719 (1893).

${ }^{2}$ Compt. rend., II4, 23 I (1891). 